\title{
Hypocalcemic vitamin D-resistant rickets
}

INSERM

\section{Source}

INSERM. (1999). Orphanet: an online rare disease and orphan drug data base.

Hypocalcemic vitamin D-resistant rickets. ORPHA:93160

Hypocalcemic vitamin D-resistant rickets (HVDRR) is a hereditary disorder of vitamin D action characterized by hypocalcemia, severe rickets and in many cases alopecia. 